\title{
The Quantitative Distribution of the Hormones of Love and Neurotransmitters at Psycho Emotional Stresses
}

\author{
Aleksidze NG* \\ Tbilisi State University, Georgia, USA
}

*Corresponding author: Nugzar G Aleksidze, Tbilisi State University, Georgia, USA, Email: aleksidze.nugzar@yahoo.com

\section{Review Article \\ Volume 3 Issue 5}

Received Date: April 21, 2018

Published Date: May 28, 2018

\section{Abstract}

In the article the results of studies of quantitative changes in the hormones of love under psycho emotional stress are examined. It is shown that for all emotional loads, the brain plays the leading role in pacing the psycho emotional load by mediating the hormones of love (oxytocin, vasopressin) and neurotransmitters (epinephrin, serotonin, dopamin) which are controlled by the brain. Three forms of love are considered: lust, attraction and attachment, which when men and elsewhere are really amazed by love and cannot think of another. The libido is also estimated-the passion of love by Freud and Jung. The data on five structural formations of the brain responsible for the attraction of love are given. It is shown that pray is one of the ways of psychotherapy.

Keywords: Love Hormones; Neurotransmitters; Three phases of love

\section{Introduction}

The study of hormones of love and the mechanism of their action is one of the actual problems of psychology and medicine. The participation of hormones of love (oxytocin, vasopressin) and neurotransmitters (epinephrine, serotonin, dopamine), widely considered in textbooks and academic journals in the connection with the formation of the three phases of love (lust, attraction, attachment) and the activation of sexual activity between heterozygous individuals [1-3].

Hormones are biologically active compounds through which all vital processes are carried out and regulated $[1,4]$. Hormones produced in specialized cells of glands of internal secretion enter the bloodstream, bind to receptors of target cells and exert a regulatory influence on metabolism and physiological functions [5].
Hormones, carried by blood, serve as humoral regulators of certain processes in various organs and systems [6,7]. Effects of hormones actions: 1. Occur in extremely low concentrations - in the range from $10^{-6}$ to $10^{-12}$ M. 2. The realization of hormonal effects is carried out through the protein receptors by intracellular secondary mediators, messengers. 3 . Effects of hormones are carried out by changing the rate of either enzymatic catalysis or the synthesis of enzymes - although the hormones themselves are neither enzymes nor coenzymes. 4. The central nervous system controls the action of hormones and affects their effect on the body. 5 . Between the hormones and glands of internal secretion there is both direct and feedback, which unites them in the general system of functional activity. Sex hormones are produced by the male and female sex glands, which are the main elements of the human reproductive system. Synthesized hormones are released into the bloodstream and affect all vital functions of living organisms. 


\section{Psychology \& Psychological Research International Journal}

Sex hormones provide development and functioning, having signs of a biological sex, living organisms of a male or female type and fully manifested with the onset of puberty, reached at the end of the period of puberty. Male hormones are designed to provide a male body type, the development of genital organs, hair, a set of muscle mass, a lower voice timbre. Female hormones set the female type of physique, development of mammary glands and the possibility of lactation, as well as the full development of internal female genital organs. In the female body, which has reached puberty, hormones provide the menstrual cycle, the possibility of pregnancy, childbirth and lactation [8].

In organisms, both males and females, in norm in small quantities hormones, characteristic for the opposite sex, are produced and some natural and pathological processes may be violated. This can manifest itself in changes in the functioning of the body, which temporarily or permanently acquires a part of the signs of the other sex. So, with an increased level of male sex hormones, masculinization (virilization) occurs in women, the body does not acquire proportions characteristic for women. In men with a high level of female hormones, feminization can develop and the growth of the mammary glands (gynecomastia) may occur [9,10]. Androgens include hormones: testosterone, dihydroepiandrosterone, androsterone and female - estriol and 17ß-estradiol.

In recent years, the attention of psychologists, physiologists and psychobiologists has attracted a frequent divorce of young couples and fundamental research has begun to study the neurochemistry of the psychology of love. According to professor Helen Fisher from Rutgers University (USA), there are 3 phases of love: The first phase of love (lust) is due to sex hormones testosterone and estrogen, both in men and women. The second phase of love (attraction) is the time when men and are woman really amazed by love and can not think of another, and the action of the brain is also focused on attraction. Scientist have found evidence that adrenalina, dopamine and serorotonin are involved in the attraction fhase. The third phase of love is attachment [11-15]. It was explained that the psycho emotional load in each phase of love is accompanied by quantitative changes in the "hormones of love" and neurotransmitters. Professor Fisher argues that for different people, the love can begin with any of these three phases. Professor Ayala MalachPines a psychologist at the Ben-Gurion University in Israel has published "Romantic Jealousy" and "Falling in Love" and shown that only $11 \%$ of the 493 subjects claimed that their long-term relationship began with love from the first look [16]. Unfortunately, according to Fisher's theory, romantic love lasts no more than 17 months to three years, then the hormones of love begin to sort out, weaken their effect on a person. But fortunately, a high level of these hormones can be maintained by ourselves and for a long time, we can revive their production, which will give the couple a second chance for a long relationship. Of course, if there is no mutual understanding in the pair and the desire to be close, then such methods cannot be helped very much, just as spells and conspiracies.

The question is - how people choose partner? Do women and men take into account the interest with healthy genes and the prediction of the horoscope, so that they have healthy children, unfortunately, this issue is solved only by assessing the appearance of couples, rather than their genetic conditions in the family and among their relatives.

Despite the central role of the brain in the central nervous system, little is known about the relationship between brain activation and sexual activity, and therefore, it was of great interest to find out what is happening to our brain under conditions of psychoemotional stress. In this regard, in special experiments, the method of magnetic resonance tomography was used to study the relationship between brain activation and sexual activity. A team of young healthy, heterosexual men was selected. Each subject was exposed to two video-material, consisting of erotic, dissolving and controversial elements in an unpredictable manner. To assess the physiologic state of individuals, traditional analyzes were used with the use of contrasts of formation, and as a covariate and pneumatic cuffs. The results of these analyzes for each subject were used in the analysis of random effects. In the conditions of a strong swelling penis physiological activity was observed in the right region of the half-space, including claustrum in the left caudate region and putamene, activation was predominantly found in the right hypothalgia lamus. Temel and others have shown that the mid and intraluminal nuclei of the thalamus also play an important role in the erection of the penile limb [17].

Results of studies using the method of functional magnetic resonance imaging have made it possible to measure the blood flow in the brain. Activation of a number of brain structures involved in the process of sexual activity during mating was detected. Many researchers of the psychology of love believe that three main neurotransmitters are actively involved in the 


\section{Psychology \& Psychological Research International Journal}

sexual process: adrenaline, dopamine and serotonin. As is known, the presented biological amines activate the stress response in humans, as a result of which the level of adrenaline and serotonin rises in blood and the feeling of "new love" increases [2,3,15].

Adrenaline is a hormone that is released during the human stress response and also plays a role in enhancing attraction and arousal of humans and causes a "tide of love" to the heart. Adrenaline - the hormone of stress, increases our usual capabilities. Its development in lovers leads them to the state of inspiration and the desire to "roll mountains". Adrenaline is the most important hormone that is produced in the adrenal medulla. Adrenaline is thrown into the blood during fright or in the battle, enabling the person to adapt to the situation and, therefore, has an effect on blood circulation, the muscular system and the metabolism in his body. Under the influence of this hormone, the frequency and strength of the contractions of the heart muscle increases, as well as the frequency and depth of breathing, the speed of the course of metabolic processes increases, and the performance of the muscles improves $[1,3,4]$.

It has been found that in the young couple, "afflicted with love," a high level of biogenic amine is found Dopamine, a "sensual" love hormone with specific effects: increasing attention, improving short-term memory, causing rapture, increasing courage and research feelings. According to psychobiologists, dopamine stimulates "desire and reward," the attraction to sexual activity for intense pleasure, which is actually controlled by the central nervous system, in particular, the brain. The process is accompanied by a concentration of energy and a delightful pleasure from sexual activity. As can be seen from Figure 1, that the content of dopamine in the brain under sexual activity (1), in comparison with the control (2), sharply increases (Figure 1).

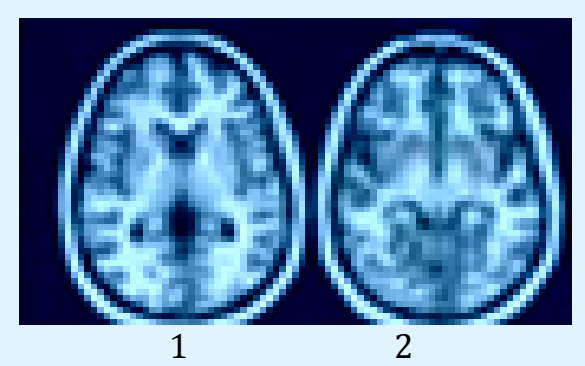

Figure 1: The content of dopamine in the brain. 1. sexual activity, 2 . control.
Dopamine - excreted in the body at the time of the onset of love, forces to achieve the goal, strive for full possession. According to neurobiologists, mental health and activation of the dopamine system precedes the very behavior that brings them satisfaction, pleasure and reward. The dopamine system provides us with a desire to receive what happiness and bliss bring us. The main function of this hormone in our body is the uplift of the mood, which is formed in the cerebral cortex. If in the body of this substance is not enough, it causes stress and depression, with its normal content, the body easily copes with stressful situations. If behavior brings satisfaction with sexual activity and justifies expectations, then the brain potentiates an appropriate amount of dopamine for the future, making this expectation equal, as well as activities of this kind pleasant. According to many scholars, it is with a romantic feeling that it is hardest to part. When the satisfaction and reciprocity of feelings are postponed, the brain still continues to activate the hormones of love and enhances the synthesis of dopamine and thereby exacerbates feelings and emotions. The amount of dopamine released depends on the specific results of the behavior or activity and the sense of satisfaction $[2,4,5]$.

Serotonin, as one of the important biogenic amines, also takes an active part in the formation of love and stimulates your beloved's thoughts of love for you. Serotonin is simultaneously responsible for reducing pain and for improving the speed of transmission of pleasant sensations. It is thanks to serotonin that the most passionate embraces and the most energetic sex do not seem to be in love painful, even if they lead to slight damage to the skin and mucous membranes. When we look at the object of tender feelings, the synthesis of serotonin begins to increase $[1,2]$.

It has been experimentally proved that early love (the phase of attraction) really enhances love relations. Psychologists believe that such love relationships force us to stay together to enter the next phase of loveattachment, but the most important function of this hormone is the uplifting of the mood that forms in the cerebral cortex. If in the body of this substance is not enough, it leads to depression. For normal production of this hormone, it is necessary to eat food rich amino acids of the precursor of serotonin tryptophan, which stimulate serotonin synthesis (Holland cheese $100 \mathrm{~g} \mathrm{/} 790 \mathrm{mg}$, fused cheese $100 \mathrm{~g} / 500 \mathrm{mg}$, rabbit meat $(100 \mathrm{~g} / 330$ $\mathrm{mg}$ ), chicken ( $100 \mathrm{~g} / 290 \mathrm{mg}$ ), beans (100 g / $260 \mathrm{mg}$ ) $[2,18]$. 


\section{Psychology \& Psychological Research International Journal}

The third phase of love - attachment is a bond that keeps couples together long enough for them to have and bring up children. Scientists believe that in this attachment feeling can participate two major hormones: oxytocin and vasopressin $[6,11]$.

Oxytocin is the hormone of love, tenderness and maternal love. Oxytocin Nanopeptide, a hormone of morality and trust contains 9 amino acids, affects emotions and is a powerful hormone secreted by men and women during orgasm $[1,20]$. Oxytocin is formed in the anterior nucleus of the hypothalamus, stored in the posterior pituitary (neurohypophysis), where it is transported by the carrier of a specific neurofizin protein. Physiological action of oxytocin is carried out by stimulation of smooth muscle fibers, mammary glands and uterus. Biological effect of oxytocin is realized through interaction with receptors of cytoplasmic membranes of organs and activation of fermentadadenylate cyclase, which catalyzes the formation of cyclic adenosine monophosphate (cAMP), the intracellular effect of which is mediated through cAMP-dependent proteinkinase [19-23]. Behind the binding of oxytocin to the cell receptors is responsible for the ring part of the molecule and, in particular, for the isoleucine residue. Isolation of oxytocin stimulates uterine stretching in late pregnancy, as well as irritation of the nipple during lactation. Oxytocin increases the sense of attachment and makes couples feel much closer to each other after they have had sex. Very interesting is the fact that before the injection of oxytocin the females were indifferent to the cries of the restless cub and even showed aggression. However, after the injection of oxytocin, the behavior of the mice became more consistent with those typical of the maternal brain, for example, they began to pick up squeaking mice [20].

Neurons sensitive to oxytocin are found in many brain structures. When the activity of these neurons was broken, women lost interest in men. Theory says that the more often a couple has sex, the deeper their love becomes. Oxytocin also helps to strengthen the connection between mother and child and is actively allocated during labor. At first, Robert Froemke and his colleges the mice showed an irregular smattering of neural impulses when they heard the baby's cries. Then, as the oxytocin was injected in, the signal evolved into a more orderly pattern typical of a maternal brain. The study showed that after transforming of neuronal activity, maternal psychological behaviour changed to and mother make to respond to pup calls. It is also responsible for ensuring that the mother's breast automatically releases milk under the simple look or voice of her young child.

It is important to note that when in rat blocked the natural release of oxytocin, they rejected their own cubs. On the contrary, when oxytocin was injected into female rat, they displayed love and care for other rat pups, as if they were their own [25-27].

Vasopressin is another important hormone in the longterm attachment phase and is usually released after sex. In recent years, it was detected that "the hormons of love" stimulates the sexual interest of a woman to a man. Researchers have presented a mechanism involving a new population of neurons that are activated by vasopressin and oxytocin. It was found that vasopressin and oxytocin as a biologicaly sexsual signal stimulates the second phase of love attraction of males and females [28].

The prosocial neuropeptide oxytocin has been identified as a key facilitator of both interpersonal attraction and the formation of parental attachment. In this randomized placebo-controlled trial, it was provide the first behavioral evidence that the intranasal administration of oxytocin stimulates men in a monogamous relationship, but not single ones, to keep a much greater distance between themselves and an attractive woman during a first encounter. In this way, oxytocin may help to promote fidelity within monogamous human relationships [26-28].

It is important to note that often in love relationships are involved pheromones, volatile substances that come with blood to all the cells of animals and stand out on the surface of the skin with sweat glands, emitting a smell of sexual attraction. Incredibly, but the fact that the male butterfly of the night peacock eye senses the smell of an unfertilized female at a distance of eleven kilometers and flies towards it. Pheromones are a secreted or excreted chemical factor that causes a social reaction in members of the same species. Pheromones are chemicals that can act outside the body of a secreting organism in order to influence the behavior of animals. There are alarming pheromones, food path pheromones, sexual pheromones and many others that affect the physiology of behavior. Pheromones are used from the basic unicellular prokaryotes to complex multicellular eukaryotes. Their use among insects was particularly well documented. In addition, some vertebrates, plants and infusorians communicate with the help of pheromones. It has been proven that receptors located in the nose of a mammal bind to certain odorous substances, triggering a cascade 


\section{Psychology \& Psychological Research International Journal}

of signals to the brain. Depending on the volume and the ratio of substances, there are different smells - the brain in some sense reads the olfactory barcode. Consequently, scientists first realized how smell works, in 2004 Buck and Excel were awarded the Nobel Prize for this work $[1,2,4,19]$.

Proceeding from having many-literary data, we can conclude that, unfortunately or fortunately, there are no human pheromones, no molecule of pheromones in mammals has been found to date. Therefore, we can say with confidence that at the moment people do not have a pheromone, but a specific smell that attracts men to mating. Therefore, we need to be close enough to the object to read the individual alphabet of the scents of sexual attractiveness. Having caught among all the smells exactly the one on which our olfactory centers are set up, you can literally lose your head literally from the first breath. It is noteworthy that when Napoleon returned home after the battles, he asked his wife not to bathe, to be able to smell the scent of her body's smell $[2,19,21]$.

The findings, published in the journal Cell, revealed cells sensitive to oxytocin, which excite the feeling of mating in females. Neurons sensitive to oxytocin are found in many parts of the brain, but it is not clear which cells are aimed at the love hormone or how the hormone affects neurons and neuronal ensembles that process information in connection with sexual activity. It has also been found that oxytocin in men improves the ability to identify a competitive relationship; while in women it allows identification of friendship. Oxytocin is excreted in our bodies in a high concentration and in an aggressive social environment, and during positive conditions, with love, orgasm, childbirth and breastfeeding. Neurobiologist Froemke from the University of New York explored the brains of animals to understand what happens in them when injecting animals with the hormone oxytocin. Froemke and his team were reprogramming the brains of virgin mice with a single hormone injection [27]. It was found that the disordered nerve impulses first appeared in mice, then the signal became more ordered and, as oxytocin came in, when the mice heard the squeaking of the young, they exhibited behavior typical of mothers. Thus, studies have shown the unexpected nature of the effect of the hormone on the behavior of neurons, almost the brain has transformed, forcing mice to respond to the call of the young.

\section{Libido - The Passion of Love}

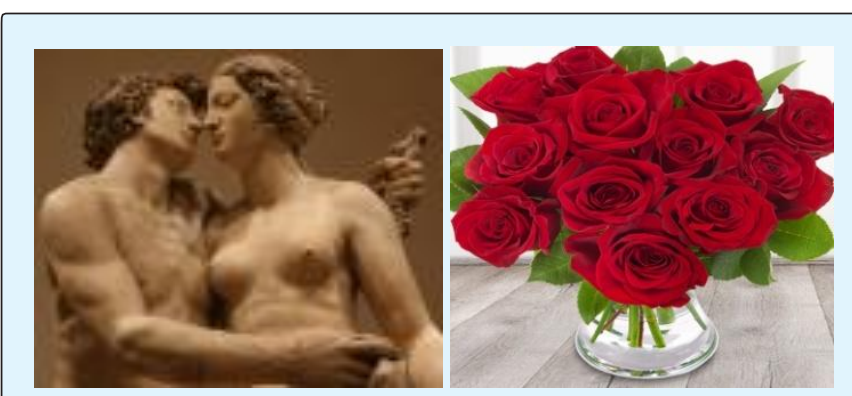

Figure 2: Neurotransmitters at Psycho Emotional Stresses

Libido (Latin lǐbīdo - lust, desire, passion, desire) iis one of the basic concepts of psychoanalysis developed by Freud, colloquially it is known as sex driver (Figure 2). Libido denotes sexual desire or sexual instinct. This term is needed to describe a variety of manifestations of sexuality. Biologically, the sex hormones and associated neurotransmitters that act upon the nucleus accumbens ( primarily testosterone and dopamine, respectively) regulate libido in humans. Freud equates the libido with Eros Plato and defined it as the energy of attraction to all that is covered by the word "love": sexual love, selfishness (narcissism), love for parents and children, universal philanthropy, etc. [21]. The term libido was used by Freud in explaining the causes of mental disorders, neurosis, as well as to describe the course of mental development of a normal person, his scientific and artistic activities. Carl Gustav Jung understands the libido as a whole mental energy or the intensity of the mental process, and sexuality - only as one of many possible manifestations of this energy, but not as a specific kind of it. Unlike Freud, Jung considered the similarity of this force to the eastern conception of the energy of Tsili Prana, and also traced the roots of this modern concept in the animistic notions of primitive peoples, which he saw as indisputable evidence that man always felt the need to find a concrete form for the psychic events.

The concept of libido began to be transferred to all kinds of love - to children, self-love, to parents, and so on. Also libido is closely related to the attraction to life and pleasure. Jung proposed to understand the libido as vitalpsychic energy, giving it even a certain mystical connotation. 


\section{Psychology \& Psychological Research International Journal}

Libido in the understanding of Jung is a manifestation of the unconscious unified energy in any life situations. The power of libidinal energy is constantly changing throughout the life of a person and can take various symbolic forms at every stage of creativity.

The female libido is a mysterious thing, and sometimes it can at all resemble a roller coaster: today there is, and tomorrow - no. However, psychologists say that this is quite a natural phenomenon, which has a number of reasons. Below, we'll present 8 interesting facts that will shed light on these naughty questions.

Experts argue that there are five most important areas of the brain that are responsible for the attraction:

1. The "Remuneration Center" (the so-called ventral striatum) reacts when a woman sees someone who is causing desire.

2. The size of the amygdala of the brain, according to scientists, directly affects the level of sexual desire.

3. The hypothalamus awards us with a hormone of pleasure, when we get something desired, for example, a passionate kiss.

4. The cerebral cortex, among other things, is also responsible for thinking about sex, which in turn causes a chain reaction that leads to the formation of sex hormones.

5. The pituitary gland stimulates the ovaries to produce estrogen, and during pregnancy and breastfeeding, it is responsible for the production of prolactin, which reduces sexual desire.
Researches of social scientists have shown that after 40 years the reproductive function of a woman decreases, and the sexual desire, on the contrary, becomes stronger. Researchers believe that this is a kind of evolutionary trick designed to increase the chances of a large offspring. Usually during this period a woman already has a permanent partner or spouse whom she trusts, and even less can take care of contraception.

\section{Prayer as One of the Ways of Psychotherapy}

The power and effectiveness of prayer is an undeniable reality for a believer of any faith and religion. The mind as a mystical force balances the consciousness. The studies of prayer states were conducted in many countries of the world on those belonging to different faiths and having different social status.

Specialists psycho physiologists conducted a global study to find out whether the activity of the brain changes during prayer. V. Slezin who examined more than 200 measurements of the brain's electroencephalograms of people belonging to different confessions, came to the conclusion that during a deep prayer the cerebral cortex seemed to be turned off and the perception of information by the person went bypassing the thought processes. As a result, he faced a paradoxical phenomenon from the point of view of physiology, the encephalogram of the brain of the praying corresponded to the state of deep sleep (coma) (Figure 3).

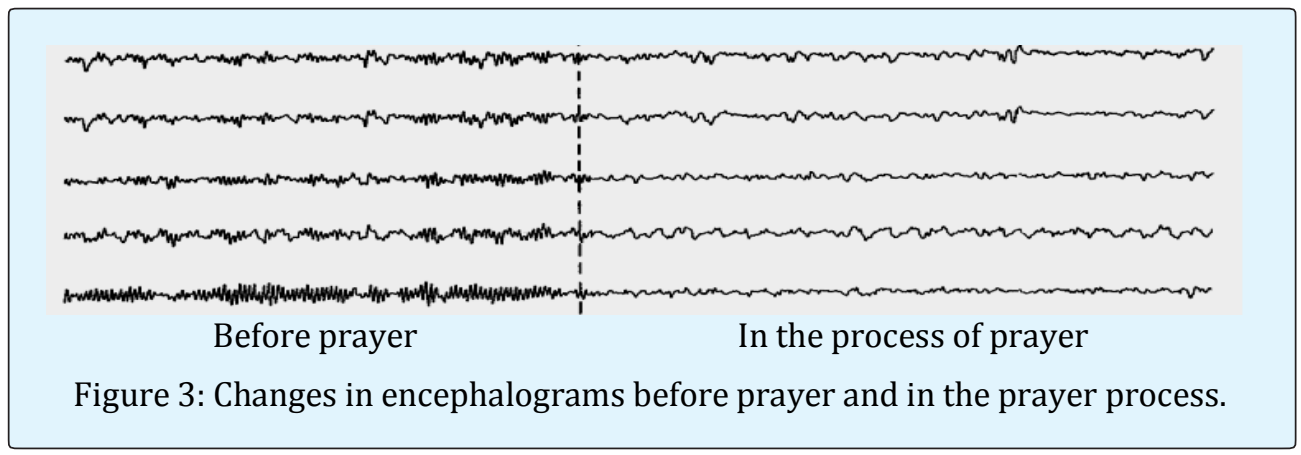

It can be seen from the figures that, "Prayerful wakefulness" is recognized by neurophysiologists as the fourth state of the brain, along with the three main ones wakefulness, slow and fast sleep, characterized by a characteristic suppression of the intensity of electrical impulses in the cerebral cortex. Such neurophysiologic processes occur regardless of what kind of faith a person professes. In addition, it should be noted that during prayer, the consumption of oxygen reduces about by $20 \%$ in a person praying, while during sleep the oxygen consumption reduces only by $8 \%$. This suggests that a prayer leads to better functioning and recovery of the body to a greater extent than sleep. 


\section{Psychology \& Psychological Research International Journal}

Another remarkable result of a prayer is the process of synchronizing the electrical rhythms of both hemispheres of the brain. As is known, usually one of the cerebral hemispheres dominates the other in the processes of the formation of electric rhythms. Such an event determines the person's inclination to imaginative (intuitive) or logical (analytical) thinking. This makes a person intellectually healty, energetic, protected from stress and according to sexologists, the worshipers become sexually more active [29].

\section{What is the Headache, Related to Sexual Activity?}

The popular rumor says that sex is one of the best remedies for headaches. Unfortunately, it is sexual activity in any of its manifestations that can cause headache. This pain is observed in $0.3 \%$ of cases among newlyweds and occurs, as a rule, in middle-aged people from 25 to 40 years. It is noted that in men similar headaches occur 4 times more often than in women. Therefore, the experts strongly recommend that all people who have ever had a headache with sexual intercourse should undergo a neuroimaging examination computer or magnetic resonance imaging of the brain and blood vessels and start medication to avoid illness and discomfort.

\section{Conclusion}

Thus, it turns out that the brain through hormones (testosterone, estrogen, oxytocin, vasopressin) and biogenic amines (adrenaline, serotonin, dopamine) through neurons and neuronal ensembles of love, through the connection of specific brain structures actively control all three phases of love (lust, attraction, attachment) in the process of mating individuals of male and female sex. Thus, all the forms of emotional pleasure are controlled by the brain [21].

\section{References}

1. Aleksidze $N$ (2016) The Basics of General Biochemistry. The Publishing House "Universal", Tbilisi, Georgia, pp: 1000.

2. Aleksidze N (2014) Fundamentals of Psychobiology. The Publishing-House of Georgian National Academy of Sciences, Tbilisi, pp. 224.

3. Zeki S (2007) The neurobiology of love. FEBS Lett 581(14): 2575-2579.
4. Aleksidze N (2013) Lectures' course in psychology. St. Andrew Georgian University, Tbilisi, p. 120 (in Georgian).

5. The 3 Stages of Love and Hormones.

6. Landgraf R, Neumann ID (2004) Vasopressin and oxytocin release within the brain: a dynamic concept of multiple and variable modes of neuropeptide communication. Front Neuroendocrinol 25(3-4): 150176.

7. Zak PJ, Kurzban R, Matzner WT (2004) The neurobiology of trust. Ann N Y Acad Sci 1032(1): 224227.

8. Blaicher W, Gruber D, Bieglmayer C, Blaicher AM, Knogler W, et al. (1999) The role of oxytocin in relation to female sexual arousal.Gynecologic and Obstetric Investigation 47(2): 125-126.

9. Gerritsen S, Bowmer AT, Hans Komen (1996) Feminization of male carp. Nature 384: 221-222.

10. Fry DM, Toone CK (1981) DDT-induced feminization of gull embryos. Science 213(4510): 922-924.

11. Cardoso C, Ellenbogen MA, Serravalle L, Linnen AM (2013) Stress-induced negative mood moderates the relation between oxytocin administration and trust: evidence for the tend-and-befriend response to stress? Psychoneuroendocrinology 38(11): 28002804.

12. Fisher H, Aron A, Brown Ll (2005) Romantic love: An fMRI study of a neural mechanism for mate choice J Comp Neurol 493(1): 58-62.

13. Fisher H (2017) From Wikipedia, the free encyclopedia.

14. The 3 Stages of Love and Hormones.

15. Kovalchuk M (2015) 5 hormones of love: how they affect our health. Suutterstok, pp: 11.

16. Ayala M Pines (1999) Falling in Love.

17. Temel Y, van Lankveld DM, Boon P, Spincemaille GH, van der Linden C, et al. (2004) Deep brain stimulation of the thalamus can affect penile erection. International Journal of Impotence Research, 16: 9194. 


\section{Psychology \& Psychological Research International Journal}

18. Aleksidze N, Tanseli Neil (2015) Influence of enviromental and social stress factors on distribution of serotonin in the brain and development of killer and self-killer organisms. New Developments in Serotonin Research. Editor: Ming D. Li. Nova Science Publisher, ISBN, pp: 51-65.

19. Aleksidze N (2008) Normal and pathological biochemistry for physicians. Publishing house Universal", pp: 1003.

20. Ferretti AI, Caulo M, Del Gratta C, Di Matteo R, Merla A, et al. (2005) Dynamics of male sexual arousal: distinct components of the brain. Neuroimage 26(4): 1086-1096.

21. Aleksidze $N$ (2017) Change in the quantitative content of the hormones of love and neurotransmitters at psycho emotional stresses. Publishing House "Nekery", Tbilisi.

22. Dulac C, O’Connell LA, Wu Z (2014) Neural control of maternal and paternal behaviors. Science 345(6198): 765-770.

23. Časopis Lékařo Českých (2000) Utváření mateřského pouta těhotenství. Development of the maternal bond during pregnancy 139(1): 5-8.
24. Aleksidze N, Balavadze M (1975) Inductive synthesis of cholinestherase in the brain at learning and training of rats. Voprosy biokhimii mozga, Yerevan 10: $97-100$.

25. Fillod O (2014) Oxytocin as proximal cause of maternal instinct: weak science, post-feminism, and the hormones of mystique, in Schmitz, Sigrid; Höppner, Grit, Gendered neurocultures: feminist and queer perspectives on current brain discourses, challenge Gender, 2, Wien: Zaglossus.

26. Scheele D, Striepens N, Güntürkün O, Deutschländer S, Maier W, et al. (2012) Oxytocin modulates social distance between males and females. J Neurosci 32(46): 16074-16079.

27. Neuroscience: The hard science of oxytocin (2011).

28. Insel TR (2010) The challenge of Translation in Social Neuroscience: A review of Oxytocin, Vasopressin, and Affiliative Behavior. Neuron 65(6): 768-779.

29. Slezin VB, Muzalevskaya NI, Uritsky VM, Rybina IYa (1998) Change in the functional state of the brain during Christian prayer. Moskow. 